\title{
Store operated calcium channels are associated with diabetic cystopathy in streptozotocin-induced diabetic rats
}

\author{
SEN YANG ${ }^{1,2}$, DONGWEN WANG ${ }^{1,2}$, XIAOMING CAO $^{1,2}$, XUHUI ZHANG $^{1,2}$, \\ XIAOBIN YUAN ${ }^{1,2}$, TIANCHENG YANG ${ }^{1,2}$ and YANG MI ${ }^{1,2}$ \\ ${ }^{1}$ First College of Clinical Medicine; ${ }^{2}$ Department of Urology, First Hospital of \\ Shanxi Medical University, Taiyuan, Shanxi 030001, P.R. China
}

Received February 5, 2017; Accepted November 1, 2017

DOI: $10.3892 / \mathrm{mmr} .2018 .8723$

\begin{abstract}
Store operated calcium channels (SOCCs) have been suggested to play a critical role in many diabetic complications. Diabetic cystopathy (DCP) is common in patients with diabetes, but the role of SOCCs in DCP is still unclear. The aim of the present study was to investigate the role of SOCCs in DCP with streptozocin (STZ)-induced diabetic rats. Specifically, the authors investigated whether SOCCs were altered in streptozocin (STZ)-induced diabetic rats and, if so, how this may contribute to the contraction of bladder detrusor strips and the intracellular $\mathrm{Ca}^{2+}$ concentration of bladder smooth muscle cells in diabetic rats. Cyclopiazonic acid (CPA, $10 \mu \mathrm{M})$ and SKF-96365 $(10 \mu \mathrm{M})$ were used to activate and inhibit SOCCs respectively, to research the effects of SOCCs on the contraction of the bladder detrusor strips in normal and STZ-induced diabetic rats at the 4th, 8th and 12 th week after the diabetic rat model was established. The changes of intracellular $\mathrm{Ca}^{2+}$ were also evaluated under confocal microscopy with pretreated Fluo-4AM. In addition, the expressions of Orail and STIM1 were detected by reverse transcription-quantitative polymerase chain reaction and western blotting at different time points. According to the results, the contractive frequency of diabetic bladder muscle strips was higher than that of controls in the 4th and 8th week. The increased fluorescence intensity was detected after using CPA and SKF-96365 in diabetic groups. The expressions of Orail and STIM1 changed in a time-dependent manner.
\end{abstract}

\section{Introduction}

Diabetes mellitus (DM) is one of the most common chronic diseases around the world. The prevalence of diabetes has

Correspondence to: Professor Dongwen Wang, Department of Urology, First Hospital of Shanxi Medical University, 56 Xinjiannan Road, Taiyuan, Shanxi 030001, P.R. China

E-mail: urology2007@126.com

Key words: store-operated calcium channels, diabetic cystopathy, $\mathrm{Ca}^{2+}$, bladder dysfunction, Orai1, STIM1 increased in recent decades (1). Diabetic cystopathy (DCP), which is a common disorder associated with diabetes in the urologic system, accounts for $\sim 80 \%$ of the diabetic population (2). The pathogenesis of DCP is a complex, multifactorial and time-dependent process. Myogenic, neurogenic and urothelial changes are the main possible causes for DCP $(3,4)$. Much evidence has suggested that the structure and function of bladder detrusor muscle is changed by DM (5-7). Much research has attempted to elucidate the mechanism of DCP, but it is still unclear, and so, the treatments for DCP are limited.

In $\mathrm{DCP}$, the contraction of the bladder is damaged depending on the diabetes duration (7). However, the exact mechanisms are far from clear. Calcium is a very important factor in the regulation of bladder smooth muscle cell (BSMC) contraction. One contraction mechanism of the SMC is driven by the release of $\mathrm{Ca}^{2+}$ from the sarcoplasmic reticulum or the endoplasmic reticulum (ER). Store-operated $\mathrm{Ca}^{2+}$ entry (SOCE) is so termed because calcium influxes through the plasma membrane when the ER $\mathrm{Ca}^{2+}$ store is exhausted. These channels are called store-operated calcium channels (SOCCs) (8). Following the description of SOCE for two decades, stromal interaction molecule 1 (STIM1) and Orai1 have been confirmed as two critical molecular components of SOCCs, according to use of RNAi technology $(9,10)$.

Presently, it is clear that SOCE participates in a wide range of pathophysiologic processes in muscles such as proliferation, growth, differentiation and migration $(11,12)$. However, in bladder detrusor muscle cells, limited research has been conducted. Recently, some studies demonstrated that SOCCs were involved in detrusor overactivity, and the amount of urothelial ATP release could be suppressed by SOCE $(13,14)$. According to clinical studies, detrusor overactivity and detrusor hyperreflexia accounts for half of the DCP population $(2,15)$. Therefore, the authors hypothesized that SOCCs might be involved in the progression of DCP. In the current study, the authors investigated the role of SOCCs in the regulation of bladder contraction and intracellular $\mathrm{Ca}^{2+}$ of BSMCs in STZ-induced diabetic rats at different time points.

\section{Materials and methods}

Experimental animals. A total of 60 female Sprague-Dawley rats (weight, 230-270 g; age, 4-6 weeks) were used and matched 
by date of birth. Animals were caged in a $12 \mathrm{~h}$ light/dark cycle, constant temperature and humidity room with free access to water and food. The rats were randomly divided into six groups: DM group for 4 weeks (DM4W), for 8 weeks (DM8W) and for 12 weeks (DM12W); the normal control group for 4 weeks (N4W), for 8 weeks (N8W) and for 12 weeks (N12W). Diabetes was induced after a $24 \mathrm{~h}$ fast by a single intraperitoneal injection of $50 \mathrm{mg} / \mathrm{kg}$ STZ (Sigma-Aldrich; Merck KGaA, Darmstadt, Germany) dissolved in $0.1 \mathrm{M}$ citrate buffer solution, $\mathrm{pH}$ 4.5. The normal controls were treated with vehicle only. At 3 days after the treatment, blood samples were collected by cutting the tail to evaluate the blood glucose level with an automatic glucometer (Accu-Check; Roche Diagnostics, Basel, Switzerland). Provided the blood glucose lever was $>300 \mathrm{mg} / \mathrm{dl}$, the rats were considered to have reached the standard of the diabetic rat model and were suitable for the following study. The body weights and blood glucose levels of all the rats were measured before the STZ injection and after the rats were sacrificed by a single intraperitoneal injection of pentobarbital $(200 \mathrm{mg} / \mathrm{kg})$, when the wet bladder weight was recorded. The bladders harvested from each rat were sliced into three parts for further studies. The ventral part of the bladder was prepared for bladder smooth muscle strips. The rest of the bladder was divided into two parts equally. One of these was prepared for bladder smooth muscle cells. Meanwhile, the other tissue was rapidly frozen in liquid nitrogen and stored at $-4^{\circ} \mathrm{C}$ for western blotting and reverse transcription-quantitative polymerase chain reaction (RT-qPCR). The experimental protocol was approved by the Laboratory Animal Research Committee of Shanxi Medical University (Taiyuan, China).

Preparation for bladder smooth muscle strips in vitro. The different experimental rats were sacrificed at 4,8 and 12 weeks respectively. Bladders were harvested and dipped into $4^{\circ} \mathrm{C}$ Krebs (containing $119 \mathrm{mM} \mathrm{NaCl}, 4.7 \mathrm{mM} \mathrm{KCl}, 1.2 \mathrm{mM}$ $\mathrm{KH}_{2} \mathrm{PO}_{4}, 1.2 \mathrm{mM} \mathrm{MgSO}$. $7 \mathrm{H}_{2} \mathrm{O}, 25 \mathrm{mM} \mathrm{NaHCO}, 2.5 \mathrm{mM}$ $\mathrm{CaCl}_{2}$ and $11 \mathrm{mM}$ glucose, $\mathrm{pH}$ adjusted to 7.35 with $\mathrm{NaOH}$ ) solution immediately. The urothelium and submucosa layers were removed by using microinstruments under a microscope (Motic, SMZ-168 Series; China Group Co., Ltd., Xiamen, China; http://www.motic.com/Indu_Stereo/product_432. $\mathrm{html}$ ) and were longitudinally cut into $3 \times 3 \times 8 \mathrm{~mm}$ strips from the ventral bladder. Bladder strips were fixed between electrodes and an automatic organ bath (Panlab; Harvard Apparatus, Holliston, MA, USA) containing $10 \mathrm{ml}$ Krebs solution inflated with $95 \% \mathrm{O}_{2}$ and $5 \% \mathrm{CO}_{2}$ at $37^{\circ} \mathrm{C}$, as described previously (16). Following $30 \mathrm{~min}$, the SOCCs agonist cyclopiazonic acid (CPA, $10 \mu \mathrm{M}$ ) (Sigma-Aldrich; Merck KGaA) was added into the Krebs solution and the inhibitor SKF-96365 (10 $\mu \mathrm{M}$; Sigma-Aldrich; Merck KGaA) was added into the Krebs solution after $5 \mathrm{~min}$. The spontaneous contractive frequency and amplitude of BSM strips were recorded $\sim 5$ min for each intervention after the spontaneous contractions of bladder strips were detected by PowerLab system and the data were analyzed by LabChart version 7.3.7 (AD Instruments, Bella Vista, Australia).

Isolation and culture of bladder smooth muscle cells. Bladder smooth muscle cells (BSMCs) were isolated by enzymatic
Table I. Primer sequences and product length.

Product

Gene Primer sequences length (bp)

Orai1 Forward: 5'-ccataagacggaccgacagt-3' 132

Reverse: 5'-gggaaggtgaggacttaggc-3'

STIM1 Forward: 5'-tggagctgccacagtatgag-3'

Reverse: 5'-tgattgtggcgagtcaagag-3'

$\beta$-actin Forward: 5'-gtcaggtcatcactatcggcaat-3'

Reverse: 5'-agaggtctttacggatgtcaacgt-3'

STIM1, stromal interaction molecule 1.

dissociation method. Briefly, BSM tissues were cut into pieces and digested in D-Hanks solution containing $0.4 \mathrm{mg} / \mathrm{ml}$ type-II collagenase and $0.4 \mathrm{mg} / \mathrm{ml}$ bovine serum albumin at $37^{\circ} \mathrm{C}, 5 \%$ $\mathrm{CO}_{2}$ and $95 \% \mathrm{O}_{2}$ condition for 40-60 min in HERAcell 150i (Thermo Fisher Scientific, Inc., Waltham, MA, USA). BMSCs were cultured in glass-bottom cell culture dishes at $37^{\circ} \mathrm{C}, 5 \%$ $\mathrm{CO}_{2}$ and $95 \% \mathrm{O}_{2}$ condition for confocal microscopy. BMSCs from each animal bladder were cultured in one dish for $24 \mathrm{~h}$.

Measurement of cytosolic $\mathrm{Ca}^{2+}$ in BMSCs. Cells cultured for $24 \mathrm{~h}$ were loaded with $4 \mu \mathrm{M}$ Fluo-4AM. Then, cells were washed with Hanks solution three times, 10 min for each wash. Finally, dishes were perfused with Tyrode solution $(118 \mathrm{mM}$ $\mathrm{NaCl}, 6.1 \mathrm{mM}$ glucose, $24 \mathrm{mM} \mathrm{NaHCO} 3,4.0 \mathrm{mM} \mathrm{KCl}$, $1.0 \mathrm{mM} \mathrm{MgCl}_{2}, 0.4 \mathrm{mM} \mathrm{NaH}_{2} \mathrm{PO}_{4}, 1.8 \mathrm{mM} \mathrm{CaCl}_{2}$ and $5.0 \mathrm{mM}$ sodium pyruvate at $\mathrm{pH} 7.35)$ and cells were scanned (1 image for $5 \mathrm{sec}$ ) under confocal microscopy (FlouView-FV1000; Olympus Corporation, Tokyo, Japan). The method followed was as reported previously (14). The SOCCs agonist CPA $(10 \mu \mathrm{M})$ and the inhibitor SKF-96365 $(10 \mu \mathrm{M})$ were added into the Tyrode solution after $5 \mathrm{~min}$. The fluorescence values of BSMCs were collected $\sim 5$ min after each intervention. The ratios of fluorescence values of BSMCs (F1) and background fluorescence values (F0) were calculated for comparison in different groups. The data was collected and analyzed with FluoView 1.7a software (Olympus Corporation).

$R T$ - $q P C R$. The bladder tissue from each animal was homogenized and total RNA was extracted from the bladder tissues using TRIzol reagent (Sangon Biotech Co., Ltd., Shanghai, China). The extracted RNA was dissolved in diethylpyrocarbonate-treated water. The cDNA was synthesized using a reverse transcription kit (cat. no. K1622; Thermo Fisher Scientific, Inc.). The sequences of the primers used are listed in Table I. RT-qPCR was performed with FastStart Universal SYBR-Green Master (Roche Applied Science, Penzberg, Germany) using the following cycle settings: Heating to $94^{\circ} \mathrm{C}$ for $10 \mathrm{~min}$ and amplification for 45 cycles at $94^{\circ} \mathrm{C}$ for $15 \mathrm{sec}$ and $60^{\circ} \mathrm{C}$ for $60 \mathrm{sec}$. The relative mRNA expression of the Orai1 and STIM1 gene was normalized to abundance of mRNA for $\beta$-actin. The data was analyzed using the $2^{-\Delta \Delta \mathrm{Cq}}$ method (17).

Western blot analysis. The bladder tissue lysis solution was prepared using an extraction reagents kit (cat. 
Table II. Body weight, bladder weight, and blood glucose in diabetic and control groups.

\begin{tabular}{|c|c|c|c|c|c|}
\hline \multirow[b]{2}{*}{ Group } & \multicolumn{2}{|c|}{ Body weight } & \multirow[b]{2}{*}{$\begin{array}{l}\text { Bladder weight } \\
(\mathrm{mg})^{\mathrm{a}}\end{array}$} & \multirow[b]{2}{*}{$\begin{array}{l}\text { Bladder to body } \\
\text { weight }(\mathrm{mg} / \mathrm{g})^{\mathrm{a}}\end{array}$} & \multirow[b]{2}{*}{$\begin{array}{l}\text { Blood glucose } \\
(\mathrm{mg} / \mathrm{dl})^{\mathrm{a}}\end{array}$} \\
\hline & $\begin{array}{l}\text { Before STZ } \\
\text { injection }(\mathrm{g})\end{array}$ & $\begin{array}{l}\text { At the time point } \\
\text { of sacrifice }(\mathrm{g})^{\mathrm{a}}\end{array}$ & & & \\
\hline N4W $(n=10)$ & $213.5 \pm 7.4$ & $298.5 \pm 13.8$ & $111.5 \pm 4.7$ & $0.374 \pm 0.012$ & $106.9 \pm 9.1$ \\
\hline N8W (n=8) & $244.9 \pm 6.8$ & $387.0 \pm 13.8$ & $125.2 \pm 3.2$ & $0.324 \pm 0.011$ & $110.2 \pm 11.3$ \\
\hline N12W (n=9) & $251.6 \pm 6.0$ & $449.4 \pm 14.6$ & $132.2 \pm 5.1$ & $0.294 \pm 0.012$ & $96.86 \pm 10.5$ \\
\hline DM4W (n=8) & $220.9 \pm 5.7$ & $201.4 \pm 13.1$ & $201.7 \pm 10.8$ & $1.000 \pm 0.048$ & $435.9 \pm 17.1$ \\
\hline DM8W (n=8) & $245.4 \pm 6.2$ & $227.9 \pm 9.0$ & $218.8 \pm 14.1$ & $0.960 \pm 0.053$ & $452.6 \pm 11.8$ \\
\hline DM12W (n=7) & $257.3 \pm 6.8$ & $271.9 \pm 11.0$ & $245.8 \pm 9.6$ & $0.904 \pm 0.032$ & $432.5 \pm 15.1$ \\
\hline
\end{tabular}

Data presented as mean \pm standard deviation. ${ }^{\text {a }}<0.05$ vs. control groups, analyzed by two-tailed Student's t-test. STZ, streptozocin.

no. PROTTOT-1KT; Sigma-Aldrich; Merck KGaA), according to the manufacturer's protocol. The protein concentrations were determined by using a bicinchoninic acid protein assay kit (cat. no. P1551; Applygen Technologies Inc., Beijing, China). Equal amounts of protein extract (40 $\mu \mathrm{g} /$ lane) from all specimens were separated by $15 \%$ SDS-PAGE for STIM1 and $10 \%$ SDS-PAGE for Orai1 and $\beta$-actin, then electroblotted onto a $0.45 \mu \mathrm{m}$ polyvinylidene fluoride membrane in a transfer buffer. The membranes were blocked with $5 \%$ fat-free milk for $1 \mathrm{~h}$ and incubated overnight at $4^{\circ} \mathrm{C}$ with primary antibodies: Orial (cat. no. sc-68895; diluted 1:200; Santa Cruz Biotechnology, Inc., Dallas, TX, USA); STIM1 (cat. no. ab108994; diluted 1:1,000; Abcam, Cambridge, UK); $\beta$-actin (cat. no. sc-47778; diluted 1:1,000; Santa Cruz Biotechnology, Inc.). After being washed with TBST (TBS, $0.1 \%$ Tween-20), the incubation with secondary antibody (goat anti-mouse, cat. no. sc-2005 and goat anti-rabbit, cat. no. sc-2004; diluted 1:10,000; Santa Cruz Biotechnology, Inc.) conjugated to horseradish peroxidase was performed for $1 \mathrm{~h}$ at room temperature. Then, the immunoreactive bands were shown with a chemiluminescence detection solution (KL140454; Pierce; Thermo Fisher Scientific, Inc.). The film was scanned and analysed with Scion imaging software version 4.0.3.2 (Scion Corporation, Frederick, MD, USA). $\beta$-actin was used as a loading control.

Statistical analysis. All data were presented as mean \pm standard deviation. Data were analyzed by Student's t-test and one-way analysis of variance tests. $\mathrm{P}<0.05$ was considered to indicate a statistically significant difference. The data were analyzed with SPSS software (version, 13.0; SPSS, Inc., Chicago, IL, USA).

\section{Results}

General characteristics. All of the 30 STZ-induced DM rats were established successfully according to the standard of a fasting blood glucose level of $>300 \mathrm{mg} / \mathrm{dl}$. A total of 4 rats died in the first 3 days after the injection with STZ, possibly due to the intolerance to the toxicity of STZ. Another 3 rats in the DM groups died from the intestinal obstruction. A total of 3 rats in the control groups died in the first week before treatment, and the etiology of these unexpected deaths may be environmental changes. Table II presents the mean blood glucose levels, initial and terminal body weights, and the bladder weights. Similar to other investigations, the mean blood glucose levels and bladder weights in the diabetic groups increased significantly, while the mean body weights were decreased significantly, compared with the control groups. Because a number of 10 rats were lost, 47 rats were used for the study (7 rats in the D12W group, 8 rats each in the other five groups).

The frequencies of contractions in DM rats changed significantly after activation or inhibition of SOCCs. The changes of contractions of bladder detrusor strips are presented in Fig. 1. The frequency variations of spontaneous contraction were increased significantly in the $\mathrm{DM} 4 \mathrm{~W}$ group $(\mathrm{t}=3.776, \mathrm{P}=0.002$, $\mathrm{n}=8)$ and the DM8W (t=2.282, $\mathrm{P}=0.039, \mathrm{n}=8)$ group following activation of SOCC with CPA $(10 \mu \mathrm{M})$, compared with the control groups (Fig. 1C). Among these three DM groups, the DM12W group was significantly lower than the other two groups (DM12W vs. DM4W, P=0.039; DM12W vs. DM8W, $\mathrm{P}=0.012, \mathrm{n}: 8$ for DM4W, 8 for DM8W, and 7 for DM12W). Despite there being no significant differences between DM groups and control groups, the amplitudes of contractions decreased in all experiment groups after activation of SOCCs.

After the addition of SKF-96365 $(10 \mu \mathrm{M})$ to the bath, the frequencies of spontaneous contraction decreased and the amplitudes of spontaneous contraction increased in all experimental groups, compared to the time of adding CPA only. The frequency variations were significantly changed in the DM4W group $(\mathrm{t}=-3.750, \mathrm{P}=0.02, \mathrm{n}=8)$ and the DM8W group $(\mathrm{t}=-2.593, \mathrm{P}=0.021, \mathrm{n}=8)$, compared with the control groups (Fig. 1D). Among these three DM groups, the DM12W group was significantly higher than the other two groups (DM12W vs. DM4W, $\mathrm{P}=0.004$; DM12W vs. $\mathrm{DM} 8 \mathrm{~W}, \mathrm{P}=0.021, \mathrm{n}=8$ for DM4W, $n=8$ for DM8W and $n=7$ for DM12W). The amplitudes increased to some extent compared to CPA only, and there were no significant differences between DM groups and control groups.

The intracellular $\mathrm{Ca}^{2+}$ was changed significantly in BSMCs of DM rats by activation or inhibition of SOCCs. The changes of fluorescence values in BSMCs are indicated 
A N4W

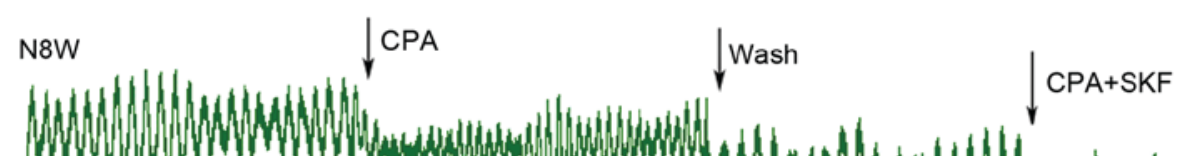

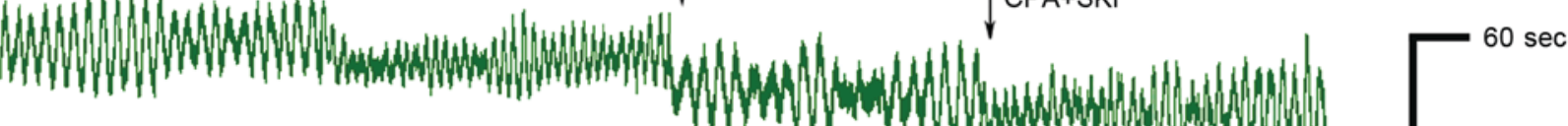
N12W $0.15 \mathrm{~g}$

B

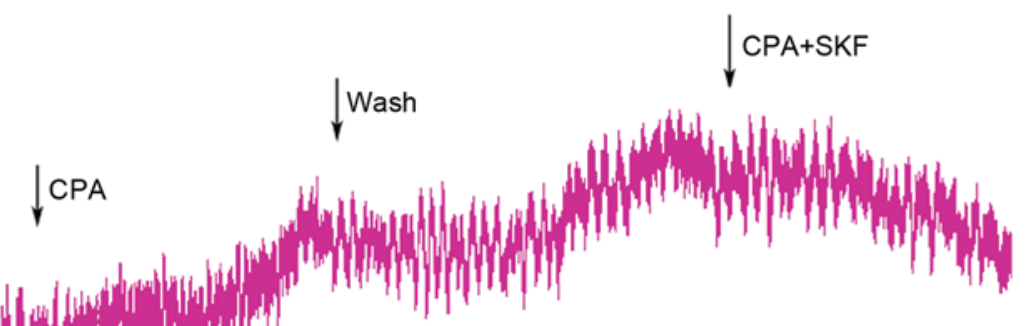

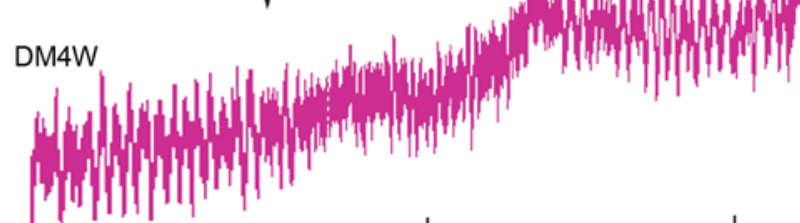
Why

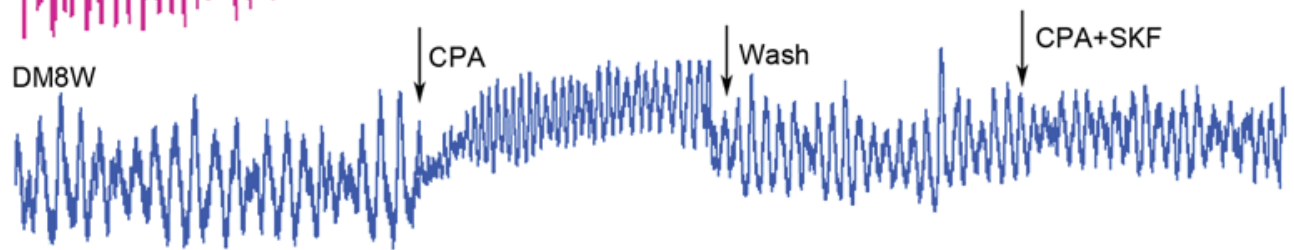

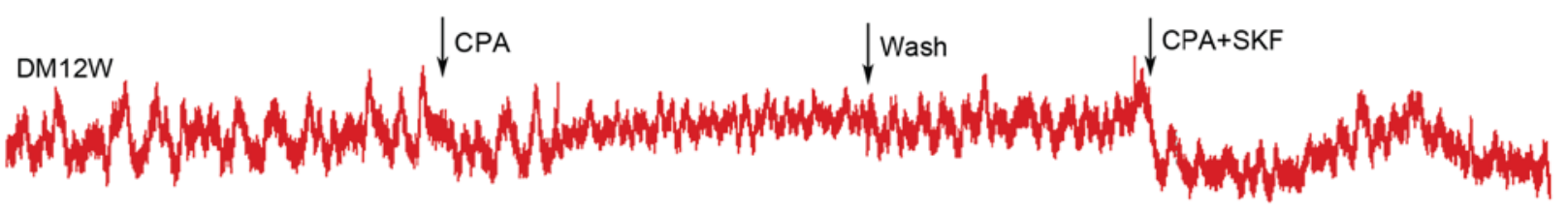

C

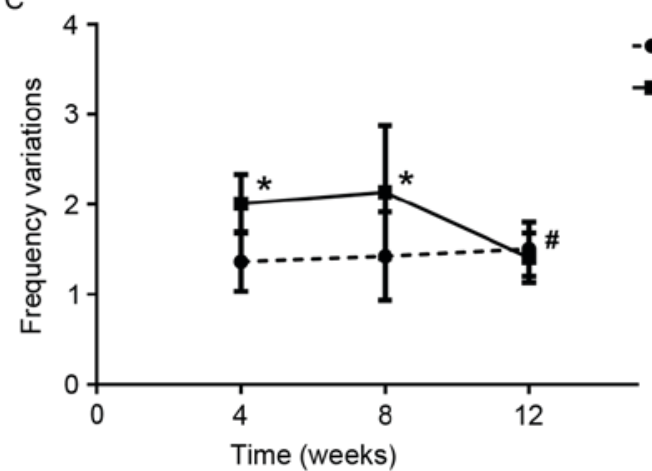

D

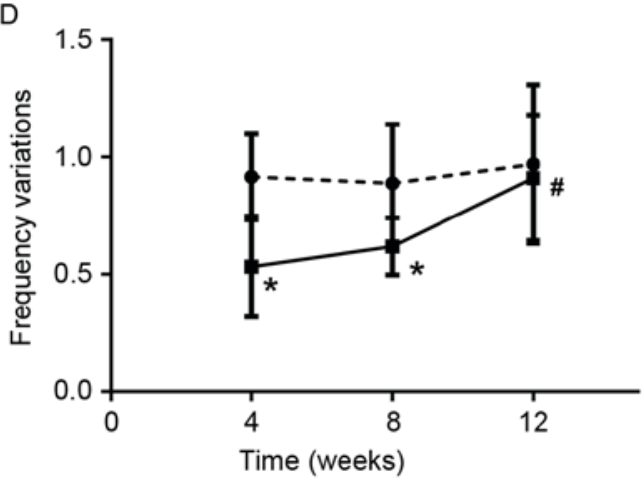

Figure 1. Changes of contractions of bladder detrusor strips after activation and inhibition store operated calcium channels. (A) Changes of contractions of bladder detrusor strips in control groups. (B) Changes of contractions of bladder detrusor strips in DM groups; (C) Changes of contractive frequency of bladder detrusor strips. ${ }^{*} \mathrm{P}<0.05$ vs. control groups after using CPA. (D) Changes of contractive frequency of bladder detrusor strips * $\mathrm{P}<0.05$ vs. control groups after using SFK-96365. Among diabetic groups, ${ }^{\#} \mathrm{P}<0.05$ vs. DM4W and DM8W groups. DM, diabetes mellitus; CPA, cyclopiazonic acid; SKF, SKF-96365.

in Fig. 2. Following activation of SOCCs with CPA, the F1/F0 increased in DM4W and DM8W groups and reached its peak in the 8th week, then went down to the control level at the time of 12th week. Compared with control groups, the F1/F0 elevated significantly in DM4W $(\mathrm{n}=8, \mathrm{t}=4.867, \mathrm{P}=0.0002)$ and DM8W groups ( $\mathrm{n}=8, \mathrm{t}=4.203, \mathrm{P}=0.001)$ (Fig. $2 \mathrm{C}$ ). The $\mathrm{F} 1 / \mathrm{F} 0$ 

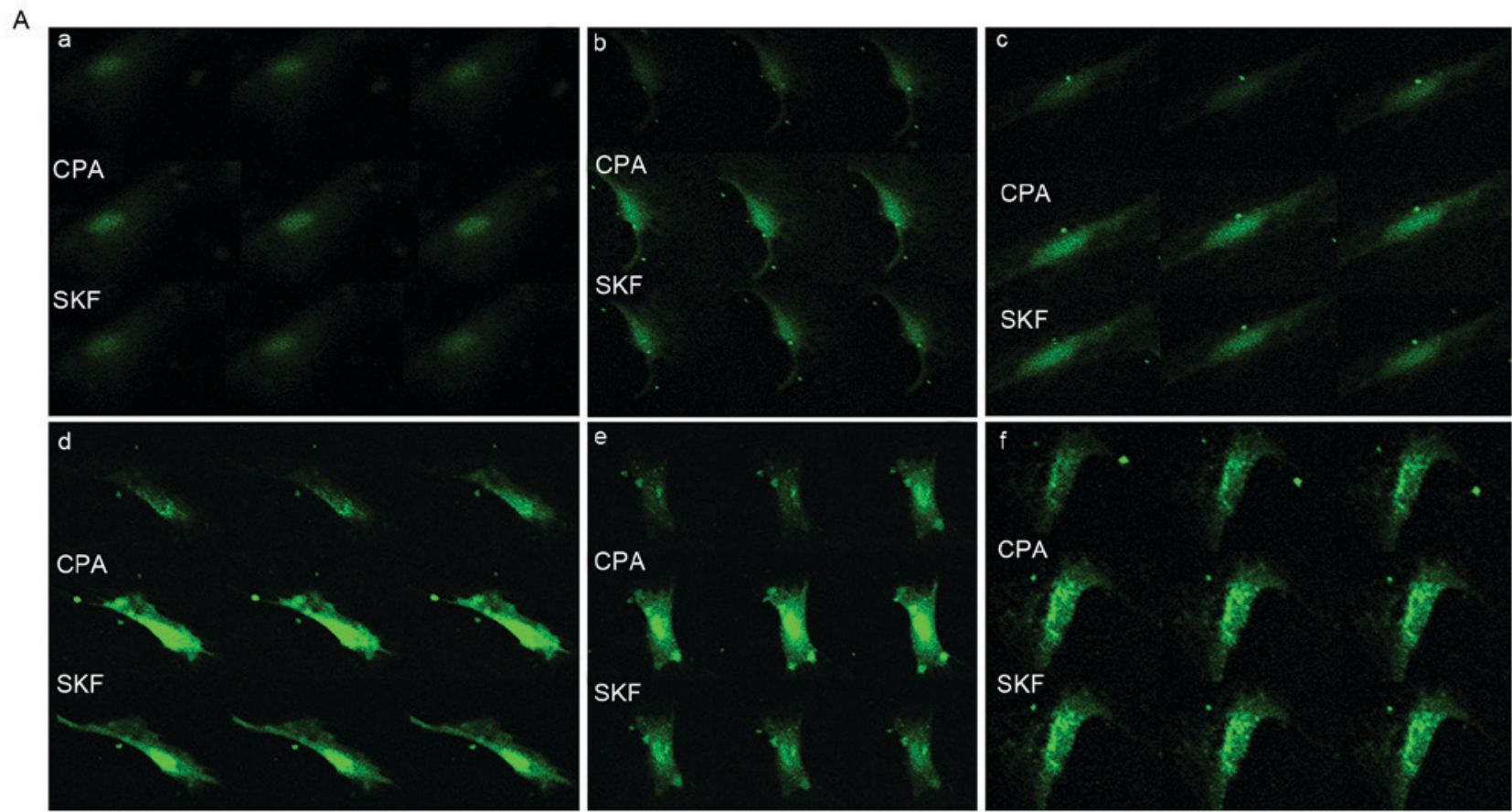

B
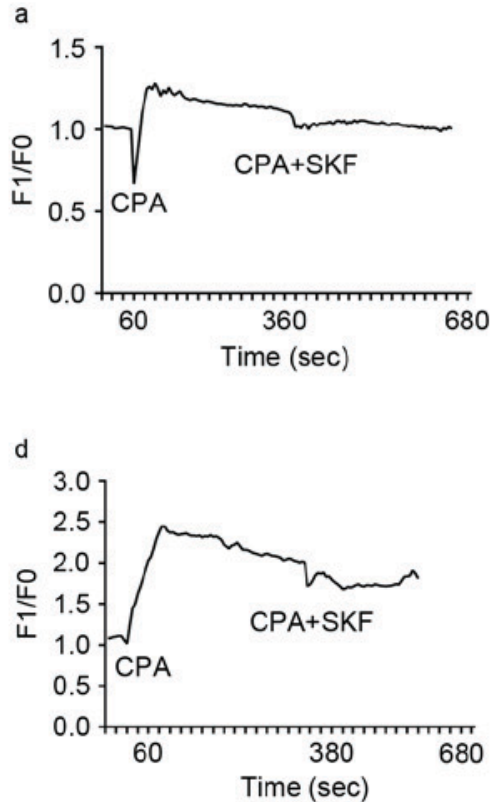

C

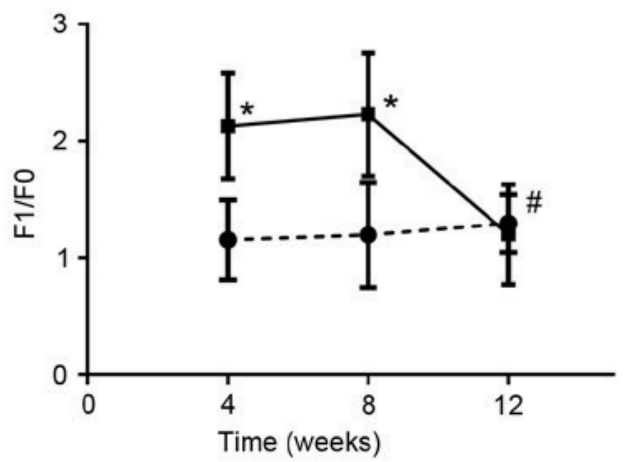

b
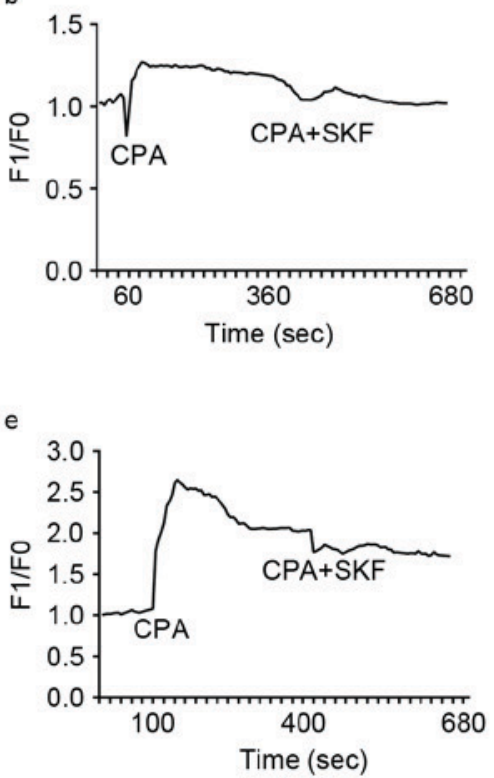

$\mathrm{D}$
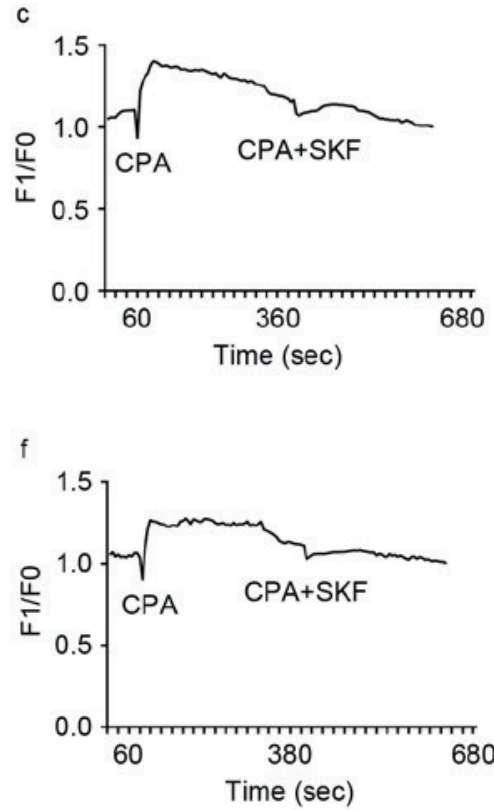
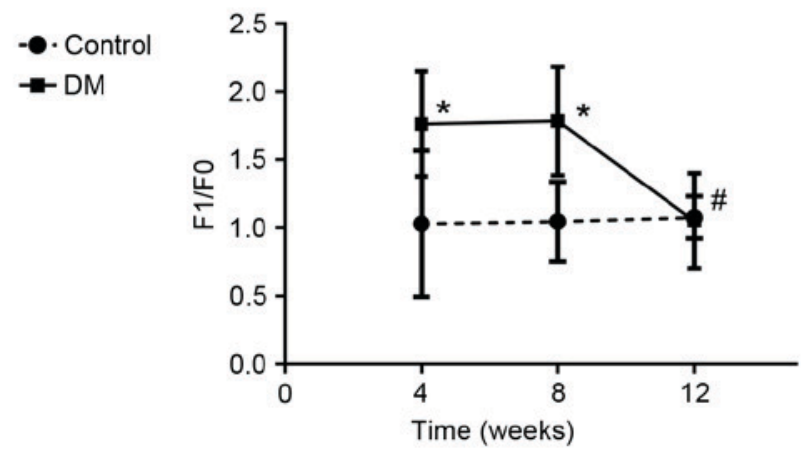

Figure 2. Changes of intracellular $\mathrm{Ca}^{2+}$ in BSMCs after activation (CPA, $10 \mu \mathrm{M}$ ) and inhibition (SKF-96365, $\left.10 \mu \mathrm{M}\right) \mathrm{SOCCs}$. (A) shown as green fluorescence intensity of Fluo-4 AM at $516 \mathrm{~nm}$. CPA, after using CPA; SKF, after using SKF-96365. (A-d, A-e and A-f) represent DM4W, DM8W and DM12W group, respectively. (A-a, A-b and A-c) represent the control groups. Magnification, $\mathrm{x} 200$. (B) The fluorescent line graphs of real-time changes of intracellular Ca ${ }^{2+}$ in BSMCs. (B-d, B-e and B-f) represent DM4W, DM8W and DM12W group respectively. (B-a, B-b and B-c) represent the control groups. (C) * $<<0.05$, vs. control groups after using CPA. (D) *P<0.05 vs. control groups after using SKF-96365. ${ }^{*} \mathrm{P}<0.05$, DM12W group compared with other two DM groups. BSMCs, bladder smooth muscle cells; CPA, cyclopiazonic acid; F1, the measured values of fluorescence intensity in BSMCs; F0, the background values of fluorescence intensity; DM, diabetes mellitus; SKF, SKF-96365. 
A

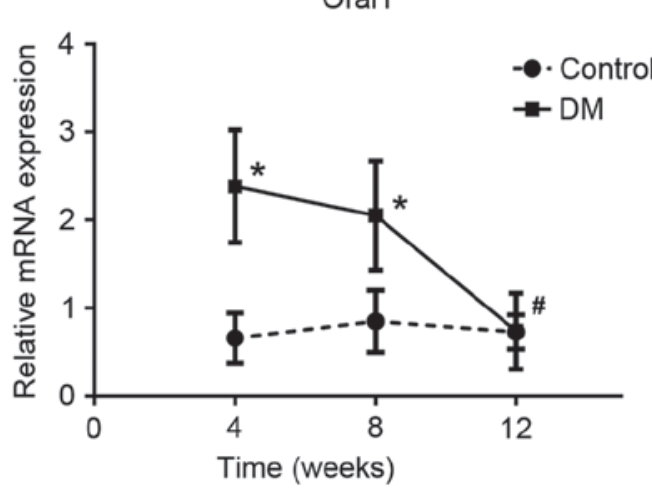

B

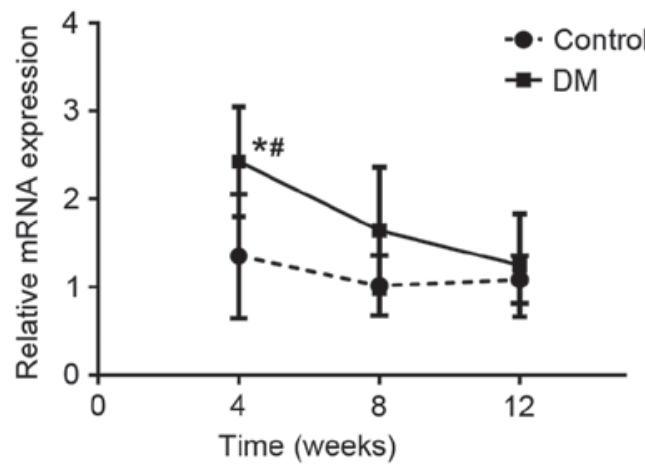

Figure 3. The relative mRNA expressions of Orai1 and STIM1 in all experimental groups. (A) "P<0.05 vs. control groups; (B) "P<0.05 vs. control groups. ${ }^{\text {"}} \mathrm{P}<0.05$ vs. other DM groups ( $\mathrm{n}=6$ for every group).

A

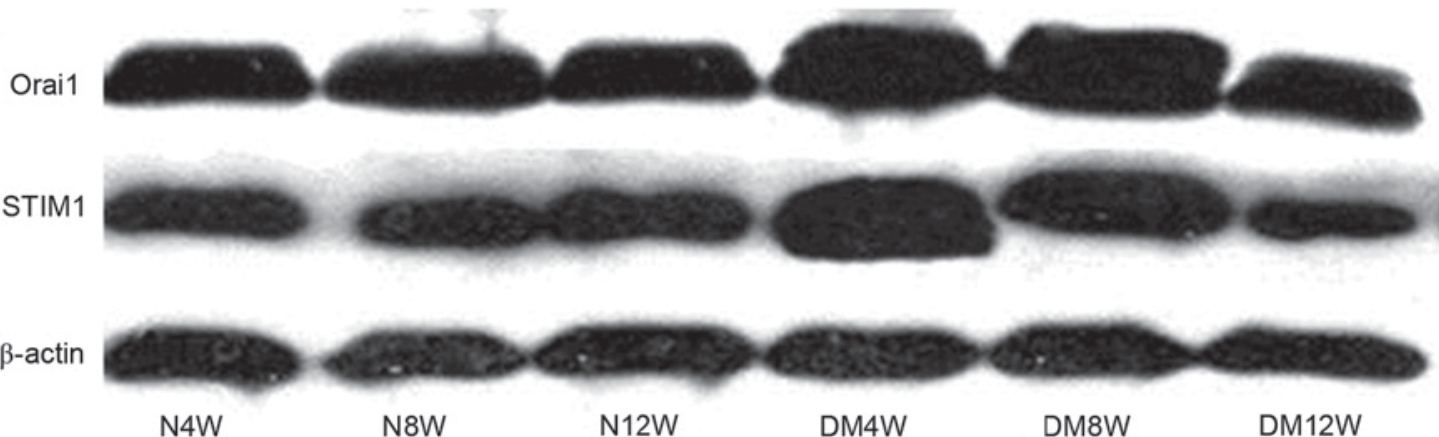

B
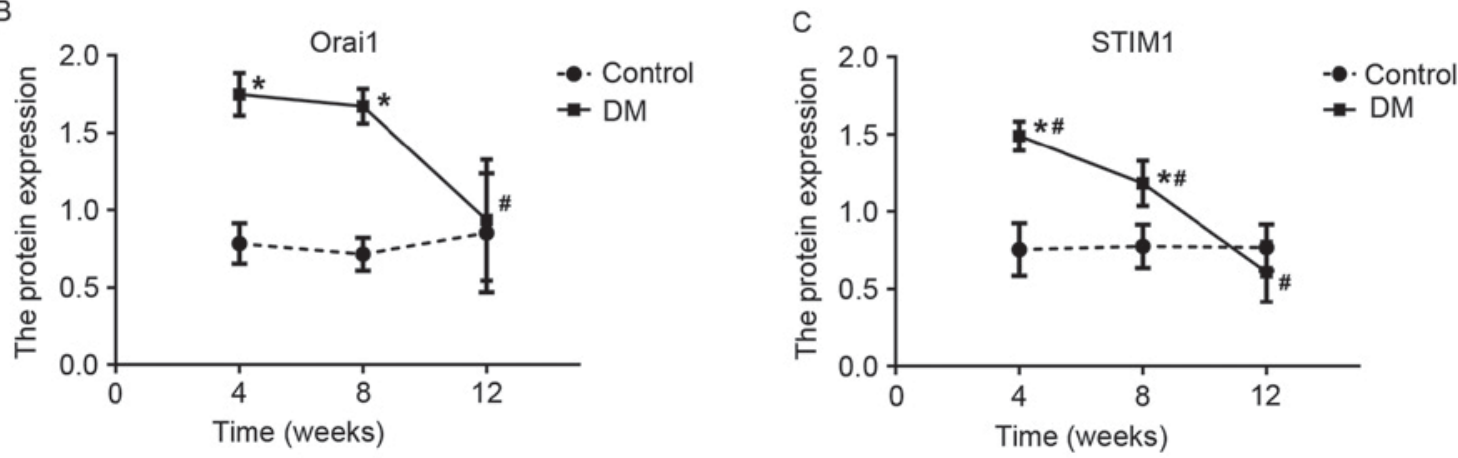

Figure 4. The expression expressions of Orai1 and STIM1 protein in all experimental groups. (A) The typical blots of Orai1, STIM1 and $\beta$-actin proteins in different groups. (B) "P $\mathrm{P}<0.05$ vs. control groups, and ${ }^{\#} \mathrm{P}<0.05$ vs. DM4W and DM8W groups. (C) "P $<0.05$ vs. control groups, and ${ }^{\#} \mathrm{P}<0.05$ among three $\mathrm{DM}$ groups ( $\mathrm{n}=6$ for every group).

decreased, when SOCCs inhibited by SKF-9365. However, the fluorescence intensity of BSMCs was still significantly higher in the DM4W $(\mathrm{n}=8, \mathrm{t}=3.141, \mathrm{P}=0.007)$ and DM8W groups $(\mathrm{n}=8$, $\mathrm{t}=3.871, \mathrm{P}=0.002$ ) than that of control groups (Fig. 2D). There was no significant difference between the DM12W group and the N4 W group after addition of CPA $(t=-0.536, P=0.601, n=7$ for DM12W, $\mathrm{n}=8$ for N4W) or SKF-96365 ( $\mathrm{t}=-0.186, \mathrm{P}=0.857$, $\mathrm{n}=7$ for DM12W, $\mathrm{n}=8$ for $\mathrm{N} 4 \mathrm{~W})$. The fluorescence intensity in the DM12W group was significantly lower than the other DM groups after activation (DM12W vs. DM4W, $\mathrm{P}=0.001$; DM12W vs. DM8W, P=0.0004, DM8W vs. DM4W, $\mathrm{P}=0.680$; $\mathrm{n}=8$ for DM4W, $\mathrm{n}=8$ for DM8W and $\mathrm{n}=7$ for DM12W) or inhibition of SOCCs (DM12W vs. DM4W, P=0.003; DM12W vs. DM8W, $\mathrm{P}=0.002$, DM8W vs. DM4W, $\mathrm{P}=0.914 ; \mathrm{n}=8$ for DM4W, $n=8$ for DM8W and $n=7$ for DM12W).
RT-qPCR analysis of Orail and STIM1. The expressions of Orail and STIM1 mRNA showed a similar trend at the three time points in SZT-induced diabetic rats, peaking at the 4th week and reaching its lowest level at the 12th week (Fig. 3). Compared with the control groups, the expressions of Orai1 mRNA were significantly higher in the DM4W ( $\mathrm{n}=6, \mathrm{t}=6.049$, $\mathrm{P}=0.0001)$ and $\mathrm{DM} 8 \mathrm{~W}$ groups $(\mathrm{n}=6, \mathrm{t}=4.122, \mathrm{P}=0.002)$ and the expressions of STIM1 mRNA were significantly higher in the DM4W group $(n=6, t=2.799, P=0.019)$. Among DM groups, the expressions of Orail and STIM1 mRNA showed a declining trend and reached their lowest levels in the 12th week. The expression of Orail mRNA in the 12th week was significantly lower than the other two DM groups (DM12W vs. DM4W, $\mathrm{P}=0.0001$; DM12W vs. DM8W, $\mathrm{P}=0.001$, DM8W vs. DM4W, $\mathrm{P}=0.329 ; \mathrm{n}=6$ for every group). The expression of STIM1 
mRNA in the 4th week was significantly higher than the other two DM groups (DM4W vs. DM8W, $\mathrm{P}=0.013$; DM4W vs. DM12W, $\mathrm{P}=0.002$, DM8W vs. DM12W, $\mathrm{P}=0.409$; $\mathrm{n}=6$ for every group).

Western blotting of Orail and STIM1. The results of western blotting indicated that Orail and STIM1 proteins in bladder tissues as single bands migrating at 38 and $77 \mathrm{kDa}$, respectively (Fig. 4A). The densitometric analysis of the bands for these proteins indicated that the expressions of Orail and STIM1 protein were similar with that of their mRNA levels in DM groups, which peaked in the 4th week and reached its lowest point in the 12th week. Compared with control groups (Fig. 4B and C), the expressions of Orail and STIM1 protein were significantly higher in DM4W and DM8W groups (Orai1: DM4W vs. N4W n=6, t=8.862, $\mathrm{P}=0.001$; DM8W vs. N8W n=6, $\mathrm{t}=10.803, \mathrm{P}=0.0004$; STIM1: DM4W vs. N4W $\mathrm{n}=6, \mathrm{t}=6.540$, $\mathrm{P}=0.003$; DM8W vs. N8W $\mathrm{n}=6, \mathrm{t}=3.495, \mathrm{P}=0.025)$. Among DM groups, the expression of Orail protein at the 12 th week was significant lower than that at 4 and 8 th weeks (DM12W vs. DM4W, P=0.007; DM12W vs. DM8W, P=0.011, DM8W vs. $\mathrm{DM} 4 \mathrm{~W}, \mathrm{P}=0.717$; $\mathrm{n}=6$ for every group). However, the expressions of STIM1 proteins were significantly different at all three time points (DM12W vs. DM4W, P=0.0003; DM12W vs. DM8W, $\mathrm{P}=0.003$, DM8W vs. DM4W, $\mathrm{P}=0.046$; $\mathrm{n}=6$ for every group).

\section{Discussion}

SOCCs were discovered in muscle cells and were found to be involved in the contraction of SMCs $(18,19)$. In the coronary artery, smooth muscle contractions via SOCCs induced by CPA were identified and that these contractions can be suppressed by pre-treated with hydrogen peroxide (18). In pulmonary arteries, CPA-induced contraction was increased in chronic hypoxia and monocrotaline-treated rats and this effect was inhibited by ginsenoside Rb1 (19). In addition, SOCCs have been proved to serve a crucial role in the progression of diabetic complications, such as diabetic nephropathy (20), diabetic vascular disease $(21,22)$ and diabetic cardiomyopathy $(23)$. CPA is a sarcoplasmic endoplasmic $\mathrm{Ca}^{2+}$-ATPase pump inhibitor, and is widely used to deplete intracellular stores in various tissues. SKF-96365 may cause a significant reduction of the transient $\mathrm{Ca}^{2+}$ release initiated by $\mathrm{CPA}$ and directly inhibit $\mathrm{Ca}^{2+}$ entry through SOCC (24). CPA and SKF-96365 are commonly used SOCC agents and have been used as pharmacological tools to study SOCE $(25,26)$.

In the present study, the authors found that the contractive frequencies of BSM strips elevated significantly in the 4th and 8th week and declined to the control level in the 12 th week in DM groups by the activation of SOCCs, which implied that the SOCCs played a critical role in regulation of the contractive frequency of the bladder in diabetic rats. However, the effect of diabetes on bladder smooth muscle contraction was inconsistent. Waring and Wendt (27) reported significantly more force in CPA-treated diabetic muscles at 8th week. Compared with the control group, a reduced CPA induced bladder contraction was discovered in diabetic rats at 12 th week (28). According to the International Consultation on Incontinence-Research
Society panel recommendation (29), the time-dependent design should be developed in future research to investigate the diabetic uropathy in DM. Daneshgari et al (7) suggested that the contraction changes of DSM strips in diabetic rats were time-dependent. Diabetic bladders may undergo a transition from a compensated to a decompensated state and transition in the streptozotocin rat model may begin 9 to 12 weeks following induction. The discrepancies of these reports may be due to the different experimental conditions and the duration of diabetes (30).

Calcium homeostasis is a very important factor for the contraction function of SMCs. The authors measured the changes of intracellular $\mathrm{Ca}^{2+}$ concentration in BMSCs in order to explore the potential mechanisms of the contractive frequency changes. Waring and Wendt (27) suggested that there were no major impairments in either intracellular calcium regulation or contractile function in bladder smooth muscle after 8 weeks of STZ-induced diabetes. Mustafa (28) found that the CPA induced contraction of bladder strips decreased in diabetic rats at 12 th week and suggested that the $\mathrm{Ca}^{2+}$-ATPase pumps were impaired after 12 weeks of STZ-induced diabetes. In the current study, the changes of F1/F0 increased in the 4th and 8th week and declined to the control level in the 12th week in DM groups by the activation of SOCCs, which decreased when SKF-96365 was added. The results were consistent with the contraction frequency of bladder detrusor muscle strips. These results may suggest that the elevated contraction frequency was triggered by the changes of intracellular $\mathrm{Ca}^{2+}$ concentration via SOCCs.

In previous studies $(30,31)$, the voltage-gated calcium channels (VGCCs) were found to play a major role in contractile responses of bladder strips to depolarizing stimuli in STZ-induced diabetic mice (type 1 diabetes) and $\mathrm{db} / \mathrm{db}$ mice (type 2 diabetes). However, the interaction effect among $\mathrm{Ca}^{2+}$ related channels is poorly understood. Some researchers suggested that the $\mathrm{Ca}_{\mathrm{v}} 1.2$ channel, a subtype of L-VGCC, could be inhibited by STIM1induced store depletion $(32,33)$. Nguyen et al (34) found an inhibitory interaction between STIM1 and $\mathrm{Ca}_{\mathrm{v}} 3.1$, a T-type $\mathrm{Ca}^{2+}$ channel. Moreover, mitochondria were suggested to be involved in the modulation of SOCE in Alzheimer's disease (35). Mitochondria serve an important role in calcium buffering and can modulate SOCE through multiple interaction pathways, to prolong SOCE for example, but the interaction pathways are not well understood (8). One limitation of these $\mathrm{Ca}^{2+}$ concentration study results is that we are unable to rule out the contribution of non-SOCE influx in the fluorescent values. However, the increased fluorescent values induced by CPA were partly blocked by SKF-96365, which might suggest that the SOCE was involved in the process.

The molecular components of SOCCs have not been completely clarified. Some of the canonical transient receptor potential proteins have been suggested to contribute to SOCE under certain conditions, but conflicting results have been reported (36). Moreover, mammals express two STIM homologs, STIM1-2, and three Orai homologs, Orai1-3. However, less is known concerning the functions of STIM2, Orai2, and Orai3 (37). As the combination of STIM1-Orai1 is undisputed, the expressions of Orail and STIM1 were therefore studied. Chaudhari et al (20) provided 
a molecular basis for increased store-operated $\mathrm{Ca}^{2+}$ entry under high glucose and diabetes conditions in mesangial cells. They identified that the STIM1 and Orail protein levels increased following administration of high glucose $(25 \mathrm{mM})$ for 7 days. The upregulation of these two proteins were further verified in rats with 4 weeks of STZ treated type 1 diabetic rats and high-fat diet induced type 2 diabetic rats. Another study (38) reported that increased abundance of Orai1-3 and STIM1-2 was detected with enhanced SOCE in vascular endothelial cells in high glucose $(25 \mathrm{mM})$ treated for 3 days. Furthermore, the expression levels of Orai1-3 and STIM1-2 mRNAs were significantly upregulated in the aortae of Akita diabetic and STZ-induced diabetic mice. However, Estrada et al (21) reported that the expression of STIM1 protein was decreased in coronary endothelial cells in diabetic mice at 6 weeks after STZ injection. Moreover, overexpression of STIM1 alleviated the impaired ER Ca ${ }^{2+}$ refilling in diabetic coronary endothelial cells. The present study demonstrated that the expressions of Orai1 and STIM1 peaked in the 4th week and returned to the level of the control group in the 12th week, and this also paralleled the changes of intracellular $\mathrm{Ca}^{2+}$ concentration.

Taking these results into consideration together, the authors concluded that the SOCCs were involved in the pathological mechanism of DCP. However, the detailed signal pathway of SOCCs in the progression of DCP should be explored in future studies.

\section{Acknowledgements}

The present study was supported by the National Natural Science Foundation of China (grant no. 81370861).

\section{Competing interests}

The authors declare that they have no competing interests.

\section{References}

1. Cheng YJ, Imperatore G, Geiss LS, Wang J, Saydah SH, Cowie CC and Gregg EW: Secular changes in the age-specific prevalence of diabetes among U.S. adults: 1988-2010. Diabetes Care 36: 2690-2696, 2013.

2. Kaplan SA, Te AE and Blaivas JG: Urodynamic findings in patients with diabetic cystopathy. J Urol 153: 342-344, 1995.

3. Sasaki K, Chancellor MB, Phelan MW, Yokoyama T, Fraser MO, Seki S, Kubo K, Kumon H, Groat WC and Yoshimura N: Diabetic cystopathy correlates with a long-term decrease in nerve growth factor levels in the bladder and lumbosacral dorsal root Ganglia. J Urol 168: 1259-1264, 2002.

4. Hanna-Mitchell AT, Ruiz GW, Daneshgari F, Liu G, Apodaca G and Birder LA: Impact of diabetes mellitus on bladder uroepithelial cells. Am J Physiol Regul Integr Comp Physiol 304: R84-R93, 2013.

5. Wang D, Yuan X, Hu C, Zhang B, Gao H, Wang D, Chi J, Jing Q, $\mathrm{Wu} \mathrm{S}$ and Wu CL: Endoplasmic reticulum stress is involved in apoptosis of detrusor muscle in streptozocin-induced diabetic rats. Neurourol Urodyn 36: 65-72, 2017.

6. Changolkar AK, Hypolite JA, Disanto M, Oates PJ, Wein AJ and Chacko S: Diabetes induced decrease in detrusor smooth muscle force is associated with oxidative stress and overactivity of aldose reductase. J Urol 173: 309-313, 2005.

7. Daneshgari F, Liu G and Imrey PB: Time dependent changes in diabetic cystopathy in rats include compensated and decompensated bladder function. J Urol 176: 380-386, 2006.

8. Prakriya M and Lewis RS: Store-operated calcium channels. Physiol Rev 95: 1383-1436, 2015.
9. Zhang SL, Yu Y, Roos J, Kozak JA, Deerinck TJ, Ellisman MH, Stauderman KA and Cahalan MD: STIM1 is a $\mathrm{Ca}^{2+}$ sensor that activates CRAC channels and migrates from the $\mathrm{Ca}^{2+}$ store to the plasma membrane. Nature 437: 902-905, 2005.

10. Prakriya M, Feske S, Gwack Y, Srikanth S, Rao A and Hogan PG: Orail is an essential pore subunit of the CRAC channel. Nature 443: 230-233, 2006.

11. Spinelli AM, González-Cobos JC, Zhang X, Motiani RK, Rowan S, Zhang W, Garrett J, Vincent PA, Matrougui K, Singer HA and Trebak M: Airway smooth muscle STIM1 and Orail are upregulated in asthmatic mice and mediate PDGF-activated SOCE, CRAC currents, proliferation, and migration. Pflugers Arch 464: 481-492, 2012.

12. Seth M, Li T, Graham V, Burch J, Finch E, Stiber JA and Rosenberg PB: Dynamic regulation of sarcoplasmic reticulum $\mathrm{Ca}(2+)$ stores by stromal interaction molecule 1 and sarcolipin during muscle differentiation. Dev Dyn 241: 639-647, 2012.

13. Matsumoto-Miyai K, Kagase A, Yamada E, Yoshizumi M, Murakami M, Ohba T and Kawatani M: Store-operated $\mathrm{Ca}^{2+}$ entry suppresses distention-induced ATP release from the urothelium. Am J Physiol Renal Physiol 300: F716-F720, 2011.

14. Zhao B, Zhong X, Bai X, Wang Q, Song B and Li L: Changes in store-operated calcium channels in rat bladders with detrusor overactivity. Urology 84: 491.e1-e6, 2014.

15. Bansal R, Agarwal MM, Modi M, Mandal AK and Singh SK: Urodynamic profile of diabetic patients with lower urinary tract symptoms: Association of diabetic cystopathy with autonomic and peripheral neuropathy. Urology 77: 699-705, 2011.

16. He P, Deng J, Zhong X, Zhou Z, Song B and Li L: Identification of a hyperpolarization-activated cyclic nucleotide-gated channel and its subtypes in the urinary bladder of the rat. Urology 79: 1411.e7-e13, 2012.

17. Livak KJ and Schmittgen TD: Analysis of relative gene expression data using real-time quantitative PCR and the 2(-Delta Delta C(T)) method. Methods 25: 402-408, 2001.

18. Weirich J, Dumont L and Fleckenstein-Grün G: Contribution of capacitative and non-capacitative $\mathrm{Ca}^{2+}$-entry to M3-receptor-mediated contraction of porcine coronary smooth muscle. Cell Calcium 38: 457-467, 2005.

19. Wang RX, He RL, Jiao HX, Dai M, Mu YP, Hu Y, Wu ZJ, Sham JS and Lin MJ: Ginsenoside Rb1 attenuates agonist-induced contractile response via inhibition of store-operated calcium entry in pulmonary arteries of normal and pulmonary hypertensive rats. Cell Physiol Biochem 35: 1467-1481, 2015.

20. Chaudhari S, Wu P, Wang Y, Ding Y, Yuan J, Begg M and Ma R: High glucose and diabetes enhanced store-operated $\mathrm{Ca}(2+)$ entry and increased expression of its signaling proteins in mesangial cells. Am J Physiol Renal Physiol 306: F1069-F1080, 2014.

21. Estrada IA, Donthamsetty R, Debski P, Zhou MH, Zhang SL, Yuan JX, Han W and Makino A: STIM1 restores coronary endothelial function in type 1 diabetic mice. Circ Res 111: 1166-1175, 2012.

22. Curtis TM, Major EH, Trimble ER and Scholfield CN: Diabetes-induced activation of protein kinase $\mathrm{C}$ inhibits store-operated $\mathrm{Ca}^{2+}$ uptake in rat retinal microvascular smooth muscle. Diabetologia 46: 1252-1259, 2003.

23. Pang Y,Hunton DL, Bounelis P and Marchase RB: Hyperglycemia inhibits capacitative calcium entry and hypertrophy in neonatal cardiomyocytes. Diabetes 51: 3461-3467, 2002.

24. Peng G, Lu W, Li X, Chen Y, Zhong N, Ran P and Wang J: Expression of store-operated $\mathrm{Ca} 2+$ entry and transient receptor potential canonical and vanilloid-related proteins in rat distal pulmonary venous smooth muscle. Am J Physiol Lung Cell Mol Physiol 299: L621-L630, 2010.

25. Peng G, Ran P, Lu W, Zhong N and Wang J: Acute hypoxia activates store-operated $\mathrm{Ca}(2+)$ entry and increases intracellular $\mathrm{Ca}(2+)$ concentration in rat distal pulmonary venous smooth muscle cells. J Thorac Dis 5: 605-612, 2013.

26. Liu H, Hughes JD, Rollins S, Chen B and Perkins E: Calcium entry via ORAI1 regulates glioblastoma cell proliferation and apoptosis. Exp Mol Pathol 91: 753-760, 2011.

27. Waring JV and Wendt IR: Effects of streptozotocin-induced diabetes mellitus on intracellular calcium and contraction of longitudinal smooth muscle from rat urinary bladder. J Urol 163: 323-330, 2000

28. Mustafa S: Effect of diabetes on the ion pumps of the bladder. Urology 81: 211.e17-e21, 2013.

29. Kirschner-Hermanns R, Daneshgari F, Vahabi B, Birder L, Oelke $\mathrm{M}$ and Chacko S: Does diabetes mellitus-induced bladder remodeling affect lower urinary tract function? ICI-RS 2011. Neurourol Urodyn 31: 359-364, 2012. 
30. Leiria LO, Mónica FZ, Carvalho FD, Claudino MA, FrancoPenteado CF, Schenka A, Grant AD, De Nucci G and Antunes E: Functional, morphological and molecular characterization of bladder dysfunction in streptozotocin-induced diabetic mice: Evidence of a role for L-type voltage-operated $\mathrm{Ca}^{2+}$ channels. $\mathrm{Br}$ J Pharmacol 163: 1276-1288, 2011.

31. Jiang X, Luttrell I, Chitaley K and Yang CC: T- and L-type voltage-gated calcium channels: Their role in diabetic bladder dysfunction. Neurourol Urodyn 33: 147-152, 2014.

32. Wang Y, Deng X, Mancarella S, Hendron E, Eguchi S, Soboloff J, Tang XD and Gill DL: The calcium store sensor, STIM1, reciprocally controls Orai and CaV1.2 channels. Science 330: 105-109, 2010.

33. Park CY, Shcheglovitov A and Dolmetsch R: The CRAC channel activator STIM1 binds and inhibits L-type voltage-gated calcium channels. Science 330: 101-105, 2010.

34. Nguyen N, Biet M, Simard E, Béliveau E, Francoeur N, Guillemette G, Dumaine R, Grandbois M and Boulay G: STIM1 participates in the contractile rhythmicity of HL-1 cells by moderating T-type $\mathrm{Ca}(2+)$ channel activity. Biochim Biophys Acta 1833: 1294-1303, 2013.
35. Ma T, Gong K, Yan Y, Song B, Zhang X and Gong Y: Mitochondrial modulation of store-operated $\mathrm{Ca}(2+)$ entry in model cells of Alzheimer's disease. Biochem Biophys Res Commun 426: 196-202, 2012.

36. Parekh AB and Putney JW Jr: Store-operated calcium channels. Physiol Rev 85: 757-810, 2005.

37. Hoth M and Niemeyer BA: The neglected CRAC proteins: Orai2, Orai3, and STIM2. Curr Top Membr 71: 237-271, 2013.

38. Daskoulidou N, Zeng B, Berglund LM, Jiang H, Chen GL, Kotova O, Bhandari S, Ayoola J, Griffin S, Atkin SL, et al: High glucose enhances store-operated calcium entry by upregulating ORAI/STIM via calcineurin-NFAT signalling. J Mol Med (Berl) 93: 511-521, 2015

(i) (9) This work is licensed under a Creative Commons Attribution-NonCommercial-NoDerivatives 4.0 International (CC BY-NC-ND 4.0) License. 